\title{
PENINGKATAN PENGETAHUAN DAN KETERAMPILAN MANAJEMEN DIABETES MELALUI PELATIHAN MANAJEMEN DIABETES PADA KADER KESEHATAN
}

\author{
Ernawati $^{*}$ \\ 1. PSIK Fakultas Kedokteran dan Ilmu Kesehatan Universitas Islam Negri Syarif Hidatatullah, Jakarta 15412, Indonesia \\ *Email:ernawatifkik@yahoo.com
}

\begin{abstract}
Abstrak
Berbagai penelitian epidemiologi menunjukkan peningkatan angka insidens dan prevalensi diabetes tipe-2 di dunia. Strategi utama upaya prevensi terhadap kejadian diabetes adalah kegiatan pendidikan kesehatan. Pendidikan kesehatan dapat diberikan pada pasien juga dapat melalui kader kesehatan sebagai pemberdayaan masyarakat. Metode penelitian ini adalah quasi experiment dengan pendekatan pretest-postest tanpa kelompok kontrol, dengan sampel 24 orang kader kesehatan Layanan Kesehatan Cuma-Cuma Jakarta. Penelitian ini bertujuan untuk mengetahui pengaruh pelatihan manajemen diabetes terhadap pengetahuan dan keterampilan manajemen diabetes pada kader kesehatan. Hasil penelitian menunjukkan pelatihan manajemen diabetes meningkatkan pengetahuan manajemen diabetes secara bermakna $(p=0,001 ; \alpha=0,05)$. Skor ketrampilan manajemen diabetes mengalami peningkatan namun tidak bermakna secara statistik $(\mathrm{p}=0,387 ; \alpha=0,05)$. Karakteristik responden meliputi umur, pendidikan, dan pengalaman tidak berpengaruh terhadap peningkatan pengetahuan dan ketrampilan manajemen diabetes.
\end{abstract}

Kata kunci: edukasi, pengetahuan, keterampilan, manajemen diabetes

\section{Abstract}

Various epidemiological studies indicate increasing rates of incidence and prevalence of type-2 diabetes in the world. The main strategy of prevention efforts on the incidence of diabetes is doing health education activities. Health education can be given to patients and also can be administered through a cadre of community health. This research method is a quasi-experiment with pretest approach postest without control groups, with a sample of 24 health cadres in a health service for charity. Purpose of this study is to determine the effect of diabetes management training on knowledge and skills of diabetes management in the health cadres. The results showed diabetes management training improve knowledge of diabetes management in cadres significantly $(p=0.001 ; \alpha=0.05)$. Scores of diabetes management skills have increased but not statistically significant ( $p=$ $0.387 ; \alpha=0.05)$. Factors include the characteristics of age, education, and experience does not affect the increased of knowledge and skills of diabetes management.

Keywords: education, knowledge, skills, management of diabetes

\section{Pendahuluan}

Berbagai penelitian epidemiologi menunjukkan ada kecenderungan peningkatan angka insidens dan prevalensi diabetes melitus (DM) tipe-2 di berbagai penjuru dunia. World Health Organization (WHO) memprediksi adanya kenaikan jumlah pasien di Indonesia dari 8,4 juta pada tahun 2000 menjadi sekitar 21,3 juta pada tahun 2030 (Perkeni, 2006).

Perawat sebagai ujung tombak pelayanan kesehatan memiliki peran sebagai edukator dan konselor dalam meningkatkan kemandirian pasien dan keluarga untuk melakukan penatalaksanaan diabetes terpadu (Hudak \& Gallo, 2005). Peran perawat tersebut dilakukan melalui intervensi keperawatan berupa pendidikan kesehatan. Pendidikan kesehatan tidak hanya dapat diberikan pada pasien tetapi juga dapat diberikan melalui kader kesehatan sebagai pemberdayaan masyarakat.

Strategi utama upaya prevensi terhadap kejadian DM adalah dilakukannya kegiatan pendidikan kesehatan. Pendidikan kesehatan bertujuan untuk meningkatkan derajat kesehatan dan mengurangi disabilitas serta mengaktualisasikan potensi kesehatan yang dimiliki oleh individu, keluarga, kelompok, dan masyarakat (Swanson \& Nies, 1997). Pendidikan kesehatan dapat dikatakan efektif apabila dapat menghasilkan perubahan pengetahuan, 
Tabel 1 Rata-Rata Usia Responden Kader Kesehatan di Layanan Kesehatan Cuma-Cuma

\begin{tabular}{ccccccc}
\hline Variabel & n & Mean & Median & SD & Min-mak & 95\%CI \\
\hline \multirow{2}{*}{ Usia } & 24 & 47,79 & 44,50 & 9,031 & $36-71$ & $43,98-51,61$ \\
\hline
\end{tabular}

menyempurnakan sikap, meningkatkan keterampilan, dan bahkan mempengaruhi perubahan di dalam perilaku atau gaya hidup individu, keluarga, dan kelompok diabetisi (Pender, Murdaugh, \& Parsons, 2002). Pendidikan kesehatan diharapkan dapat mengubah perilaku diabetisi untuk patuh terhadap saran pengelolaan DM secara mandiri.

\section{Metode}

Penelitian ini merupakan penelitian kuantitatif, dengan desain penelitian menggunakan metode quasi experiment dengan pendekatan pre-test dan posttest tanpa kelompok kontrol, dengan sampel 24 orang kader kesehatan Layanan Kesehatan CumaCuma Jakarta. Waktu penelitian efektif dilakukan selama empat minggu, mulai minggu pertama sampai minggu keempat Juni 2011. Penelitian ini bertujuan untuk mengetahui pengaruh pelatihan manajemen diabetes terhadap pengetahuan dan keterampilan manajemen diabetes pada kader kesehatan.

\section{Hasil}

Rerata usia responden adalah 47,79 tahun $(\mathrm{SD}=$ $9,031)$. Usia terendah responden 36 tahun dan usia tertinggi 71 tahun (Tabel 1). Distribusi responden berdasar pendidikan yang paling banyak adalah SMA yaitu 15 orang $(62,5 \%)$. Responden yang berpendidikan perguruan tinggi juga cukup banyak yaitu 5 orang $(20,8 \%)$, dan tidak ada kader kesehatan yang tidak berpendidikan. Distribusi responden berdasarkan pengalaman pelatihan diabetes adalah mayoritas belum pernah mengikuti pelatihan manajemen diabetes $(79 \%)$, sedangkan sisanya (21\%) pernah mengikuti pelatihan yang terkait dengan managemen diabetes.

Rerata skor pengetahuan responden pada evaluasi awal adalah 5,79 (95\% CI : 5,02-6,56). Sedangkan rerata skor pengetahuan responden pada evaluasi akhir diperoleh nilai rerata 8,04 (95\% CI : 7,30$8,78 ; \mathrm{SD}=1,756)$. Rerata skor keterampilan manajemen diabetes responden pada evaluasi awal yaitu 32,63 (95\% CI : 32,28 - 32,97). Sedang, rerata skor keterampilan managemen diabetes responden pada evaluasi akhir yaitu $36,92(95 \% \mathrm{CI}: 36,40-37,43)$.

Rerata pengetahuan kader pada tahap awal dan tahap akhir memiliki perbedaan skor yaitu 5,79 dan 8,04 . Ada perbedaan rerata pengetahuan yang bermakna pada kader sesudah diberikan perlakuan $(\mathrm{p}=$ $0,001 ; \alpha=0,05)$. Hasil ini juga menggambarkan skor rerata keterampilan pada tahap awal dan tahap akhir pada responden tidak menunjukkan nilai yang terlalu berbeda ( $p=0,387 ; \alpha=0,05)($ Tabel 2).

Hasil menunjukkan hubungan umur dengan peningkatan pengetahuan manajemen diabetes menunjukkan hubungan yang lemah/ tidak ada hubungan $(p=-0,187)$. Sedangkan, hubungan umur dengan peningkatan keterampilan manajemen diabetes menunjukkan hubungan yang sedang $(\mathrm{p}=$ 0,294 ). Keduanya berpola negatif artinya semakin bertambah umur kader semakin rendah tingkat pengetahuan dan keterampilan kader. Hasil uji statistik didapatkan tidak ada hubungan yang signifikan antara umur kader dengan skor pengetahuan maupun keterampilan manajemen diabetes kader $(\mathrm{p}=0,38 ; \mathrm{p}=0,163 ; \alpha=0,05)($ Tabel 3$)$.

Tabel 4 menunjukkan perubahan skor pengetahuan dan keterampilan paling besar yaitu tingkat pendidikan SMP. Tingkat pendidikan tidak berpengaruh terhadap peningkatan pengetahuan dan keterampilan $(p=0,525 ; p=0,255 ; \alpha=0,05)$. Hasil penelitian menunjukkan perubahan skor pengetahuan dan keterampilan banyak pada kader yang belum pernah mengikuti pelatihan manajemen diabetes. Namun pengalaman mengikuti pelatihan manajemen diabetes tidak berpengaruh terhadap peningkatan pengetahuan dan keterampilan $(\mathrm{p}=0,289 ; 0,199 ; \alpha=0,05)$. 
Tabel 2. Perbedaan Rata-Rata Skor Pengetahuan dan Ketrampilan Manajemen Diabetes Tahap Awal Dan Tahap Akhir Kader Kesehatan

\begin{tabular}{llllll}
\hline & Variabel Pen elitian & N & Mean & SD & p \\
\hline \multirow{2}{*}{ Pengetahuan } & Evaluasi awal & 24 & 5,79 & 1,817 & 0,001 \\
& Evaluasi akhir & 24 & 8,04 & 1,756 & \\
\multirow{2}{*}{ Ketrampilan } & Evaluasi awal & 24 & 32,63 & 0,824 & 0,387 \\
& Evaluasi akhir & 24 & 36,92 & 1,213 & \\
\hline
\end{tabular}

\section{Pembahasan}

Hasil analisis karakteristik responden menggambarkan bahwa dari 24 responden kader kesehatan mempunyai usia yang terdistribusi pada 43,98 51,61 tahun. Secara umum pada kisaran tersebut merupakan masa dewasa madya, dimulai pada umur 40 tahun sampai pada umur 60 tahun. Masa ini merupakan masa yang sangat baik kemampuannya, baik kemampuan fisik maupun psikologis (Hurlock, 1996). Kemampuan intelektual pada masa ini juga cukup baik dan belum mengalami kemunduran seperti pada lansia. Pernyataan ini ditunjang penelitian yang dilakukan oleh Schaie pada 1984, diperoleh hasil bahwa ternyata tidak ditemukan penurunan intelektual pada masa dewasa, setidaknya sampai usia 70 tahun. Pada 1994, Schaie kembali mengadakan penelitian dan menemukan penurunan di dalam kemampuan-kemampuan mental rata-rata dimulai usia 74 tahun (Hurlock, 1996).

Tingkat pendidikan responden yang paling banyak yaitu SMA dengan persentase $62,5 \%$. Dengan tingkat pendidikan pada kisaran kelompok tersebut diharapkan dapat menerima informasi dengan baik. Pengalaman-pengalaman di dunia pendidikan, ternyata berkorelasi positif dengan hasil skor pada testes inteligensi dan tugas-tugas pengolahan informasi (ingatan) (Verhaegen, Marcoen, \& Goossens, 1993 dalam Juliani, 2005). Kader kesehatan masyarakat seyogyanya memiliki latar belakang pendidikan yang cukup (Adi, 1995).

Distribusi responden berdasarkan pengalaman pelatihan diabetes adalah mayoritas belum pernah mengikuti pelatihan manajemen diabetes (79\%). Sedangkan, sisanya (21\%) pernah mengikuti pe- latihan yang terkait dengan managemen diabetes. Berdasarkan hasil wawancara dengan responden yang mengaku pernah mendapatkan pelatihan manajemen diabetes, didapatkan hasil bahwa kader kesehatan yang pernah mendapatkan pelatihan manajemen diabetes. Namun, hal ini hanya berupa ceramah mengenai penatalaksanaan diabetes, tetapi tidak disertai dengan latihan keterampilan seperti senam kaki, cara penyuntikan insulin, dan pengukuran kadar gula darah secara mandiri.

Rerata pengetahuan kader kesehatan pada tahap akhir setelah mendapatkan pelatihan mengalami peningkatan sebesar 9,4\% dan perbedaaan ini secara statistik memiliki nilai yang bermakna.

Peningkatan skor pengetahuan yang bermakna pada penelitian ini dapat disebabkan beberapa faktor. Menurut Notoatmodjo (1993), terdapat empat kelompok faktor yang berpengaruh terhadap keberhasilan sebuah pelatihan yakni: (1) faktor materi/ hal yang dipelajari; materi pelatihan ini adalah tentang manajemen diabetes, penyakit ini merupakan penyakit yang banyak terjadi di masyarakat sehingga responden mengatakan tertarik untuk mempelajari materi pelatihan ini. (2) Lingkungan fisik: suhu, kelembaban udara, kondisi tempat belajar dan lingkungan sosial yakni manusia dengan segala interaksinya: pelatihan dilakukan diruang yang tenang, jauh dari kebisingan dan sejuk. (3) Instrumental yang terdiri dari perangkat keras seperti perlengkapan belajar, alat peraga, dan perangkat lunak seperti kurikulum, pengajar, serta metode belajar, dan didukung dengan fasilitas pelatihan yang baik seperti adanya proyektor, sound system yang baik, hand out yang dibuat sederhana namun menarik. 
Tabel 3. Hubungan Umur terhadap Peningkatan Rata-Rata Skor Pengetahuan dan Skor Ketampilan Manajemen Diabetes pada Kader Kesehatan

\begin{tabular}{llll}
\hline & Variabel & r & \\
\hline Umur & Pengetahuan & $-0,187$ & 0,381 \\
& Ketrampilan & $-0,294$ & 0,163 \\
\hline
\end{tabular}

(4) Kondisi individual subjek belajar yakni: kondisi fisiologis kader kesehatan tidak yang mengalami gangguan pendengaran dan penglihatan sehingga dapat menyimak materi pelatihan dengan baik.

Skor rerata keterampilan pada tahap awal dan tahap akhir pada responden tidak menunjukkan nilai yang terlalu berbeda. Dapat disimpulkan tidak ada pengaruh pelatihan manajemen diabetes terhadap peningkatan skor keterampilan manajemen diabetes. Hal ini dapat disebabkan karena singkatnya waktu pelatihan (2 jam) dan tidak ada pelatihan lanjutan.

Penilaian segi keterampilan menggunakan pedoman menurut Khomsan (1995), yaitu jika dapat melakukan tindakan sesuai prosedur dan tanpa bantuan dapat dikatakan baik, jika dapat melakukan tindakan dengan sedikit bantuan dapat dikatakan cukup, dan jika tidak dapat melakukan tindakan dan dengan bantuan yang maksimal dapat dikatakan kurang. Hal ini dapat disimpulkan bahwa terdapat peningkatan keterampilan manajemen diabetes setelah dilakukan pelatihan manajemen diabetes namun peningkatan yang terjadi tidak bermakna secara statistik. Singkatnya waktu penelitian dan tidak ada pengulangan latihan keterampilan manajemen diabetes membuat skor keterampilan manajmen mengalami peningkatan yang kurang signifikan.

Hubungan umur dengan peningkatan pengetahuan maupun dengan peningkatan keterampilan manajemen diabetes, dalam hasil penelitian, menunjukkan hubungan yang lemah/tidak ada hubungan. Semakin bertambah umur kader, semakin rendah tingkat pengetahuan/keterampilan manajemen diabetes kader kesehatan. Proses belajar yang diterapkan adalah dengan metode belajar aktif, yaitu ceramah, diskusi, role play dan dibantu dengan audio visual yang mendukung seperti pemutaran video. Metode pembelajaran aktif seperti ini akan mem- buat kader memiliki pengetahuan secara intensif dengan mengaktifkan pengetahuan yang dimiliki, mengolah dan mengorganisasikan pengetahuan, sehingga pengetahuan dapat tertahan dengan erat dalam sistem penyimpan dan sulit dilupakan (Syarif, 1990). Peningkatan pengetahuan kader kesehatan melalui pelatihan sangat diperlukan agar kader kesehatan mampu memberi informasi yang tepat tentang manajemen diabetes sesuai dengan kemampuan, karena pengetahuan/kognitif merupakan domain yang sangat penting bagi pembentukan tindakan seseorang (Simon, Greene, \& Gottlieb, 1995).

Hasil penelitian ini tidak sesuai dengan pernyataan Davis dan Newton (1996, dalam Siagian, 2001) yang menyatakan bahwa terdapat hubungan antara pertambahan umur dengan kematangan pengambilan keputusan. Semakin meningkatnya umur diharapkan pemberian edukasi dapat ditransformasi secara optimal. Umur berhubungan dengan penampilan kerja seseorang baik secara kualitas maupun kuantitas (Robbins, 2003). Semakin bertambah umur, maka semakin matang seseorang (Friedman, 1998) sehingga dapat dikatakan umur dapat mempengaruhi pengetahuan, dan perilaku seseorang.

Selain umur, latar belakang pendidikan dapat mempengaruhi kemampuan seseorang (Siagian, 2001). Seseorang dengan pendidikan tinggi mempunyai tujuan, harapan, dan wawasan untuk meningkatkan kemampuan melalui perilaku yang optimal. Penelitian Djajoesman (1996, dalam Setyowati, 2003) mengatakan melalui pendidikan, seseorang dapat meningkatkan kematangan pengetahuannya, sehingga dapat membuat keputusan untuk bertindak.

Soekanto (1985, dalam Nuraini, 2002) mengemukakan bahwa pendidikan akan memberikan kesempatan kepada orang untuk membuka jalan pemikiran dalam menerima ide-ide atau nilai-nilai baru. 
Lueckenotte (2000), mengatakan tingkat pendidikan mempunyai hubungan yang kuat dengan faktor risiko kesehatan. Tingkat pendidikan mempengaruhi kemampuan seseorang untuk mendengar, menyerap informasi, menyelesaikan masalah, sistem nilai, perilaku, dan gaya hidup.

Mayoritas responden mempunyai pendidikan yang hampir sama sehingga responden relatif mempunyai kemampuan yang sama dalam memahami materi pelatihan. Tingkat pendidikan pada kisaran kelompok tersebut diharapkan dapat menerima informasi dengan baik. Namun tingkat pendidikan tidak berpengaruh terhadap peningkatan pengetahuan. Hal ini dapat disebabkan fasilitas pendidikan, pada saat ini semakin meningkat, sehingga masyarakat memiliki kesempatan untuk mendapatkan pendidikan/informasi bukan hanya dari pendidikan formal, namun juga dari non formal seperti penyuluhan/pelatihan kesehatan (Wirakartakusumah, 2000).

Perubahan skor pengetahuan dan skor keterampilan yang paling tinggi yaitu pada kader yang belum pernah mengikuti pelatihan manajemen diabetes. Namun pengalaman mengikuti pelatihan manajemen diabetes tidak berpengaruh secara signifikan terhadap peningkatan pengetahuan dan keterampilan.
Lima kader (21\%) telah mendapatkan penyuluhan tentang diabetes namun tidak disertai dengan pelatihan ketrampilan manajemen diabetes dan 19 kader (79\%) belum pernah mendapatkan pelatihan manajemen diabetes. Hal ini dapat disebabkan oleh kader kesehatan yang pernah mendapatkan penyuluhan tentang diabetes hanya mendapatkan informasi sebatas pengetahuan tanpa disertai dengan latihan keterampilan sehingga retensi pengetahuan dan keterampilan tidak terlalu baik.

Pada pelatihan diabetes ini peneliti mempunyai 2 tujuan yang diharapkan yaitu, pertama kader kesehatan memperoleh pengetahuan yang dibutuhkan, dan kedua mempunyai kemampuan untuk menerapkan pengetahuan. Dalam penelitian ini, kemampuan menerapkan keterampilan dibentuk dengan memberikan latihan secara berkesinambungan. Sebagai contoh setelah kader kesehatan mendapatkan materi manajemen diabetes akan dilanjutkan dengan keterampilan melakukan kegiatan mengukur gula darah mandiri, senam kaki, dan memberikan insulin dengan menggunakan pen insulin. Kemampuan keterampilan sebelum pelatihan, banyak kader kesehatan tidak mampu melakukan keterampilan tersebut. Setelah pelatihan, sudah banyak yang mengalami peningkatan namun masih dilakukan dengan bimbingan, belum mandiri.

Tabel 4. Perbedaan Peningkatan Pengetahuan Berdasarkan Pendidikan dan Pengalaman Pelatihan Diabetes pada Kader Kesehatan

\begin{tabular}{|c|c|c|c|c|c|c|}
\hline \multirow{2}{*}{ Variabel } & \multicolumn{3}{|c|}{ Pengetahuan } & \multicolumn{3}{|c|}{ Ketrampilan } \\
\hline & $\mathbf{n}$ & Perubahan & $\mathbf{p}$ & $\mathbf{n}$ & Perubahan & $\mathbf{p}$ \\
\hline \multicolumn{7}{|l|}{ Pendidikan } \\
\hline a. Tidak sekolah & 0 & & & 0 & & \\
\hline b. SD & 1 & 1,00 & & 1 & 2,00 & \\
\hline c. SMP & 3 & 3,33 & 0,525 & 3 & 5,00 & 0,255 \\
\hline d. SMA & 15 & 2,20 & & 15 & 4,40 & \\
\hline e. $\mathrm{PT}$ & 5 & 2,00 & & 5 & 4,00 & \\
\hline \multicolumn{7}{|l|}{ Pengalaman pelatihan } \\
\hline a. Pernah mengikuti & 5 & 1,60 & 0,289 & 5 & 3,60 & 0,199 \\
\hline b. Belum pernah mengikuti & 19 & 2,42 & & 19 & 4,47 & \\
\hline
\end{tabular}




\section{Kesimpulan}

Pelatihan manajemen diabetes meningkatkan pengetahuan manajemen diabetes secara bermakna pada kader kesehatan di layanan kesehatan cumacuma Jakarta. Pelatihan manajemen diabetes terpadu meningkatkan skor ketrampilan manajemen diabetes pada kader kesehatan di layanan kesehatan cuma-cuma Jakarta. Namun peningkatan skor keterampilan manajemen diabetes tidak bermakna secara statistik. Faktor karakteristik ibu meliputi umur, pendidikan, dan pengalaman tidak berpengaruh terhadap peningkatan pengetahuan dan ketrampilan manajemen diabetes.

Peneliti menyarankan perlu pemberdayaan kader kesehatan melalui pelatihan yang reguler oleh Dinas terkait agar dapat dihasilkan kader kesehatan yang memiliki pengetahuan dan keterampilan melakukan manjemen diabetes yang baik dan benar. Bagi Layanan Kesehatan Cuma-Cuma di wilayah Jakarta agar dapat mengembangkan pelatihan kader kesehatan secara kontinyu metode pelatihan yang lebih baik dan waktu yang lebih lama agar dapat meningkatkan pengetahuan, mempertahankan dan meningkatkan keterampilan kader kesehatan (MS, JS, RR).

\section{Referensi}

Adi, H.S. (1995). Kader kesehatan masyarakat. Jakarta: EGC.

Friedman, M.M. (1998). Family nursing: Theory and practice (3rd Ed.). California: Appleton and lange.

Hurlock, E.B. (1996). Psikologi perkembangan suatu pendekatan sepanjang rentang kehidupan (Edisi Kelima). Jakarta: Erlangga.

Hudak, C.M., \& Gallo, B.M. (2005). Critical care nursing: A holistik approach (6th Ed.). Philadelphia: Lippincott Company.

Khomsan, A. (1995). Pengukuran pengetahuan. Bandung: IPB Press.
Juliani, P. (2005). Fungsi kognitif masa dewasa lanjut. Diperoleh dari http://www.psikologi ums.net/mod.

Lueckenotte, A.G. (2000). Pengkajian gerontologi. Jakarta: EGC.

Notoatmodjo, S. (1993). Pengantar pendidikan kesehatan dan ilmu perilaku kesehatan. Yogyakarta: Penerbit Andi Offset.

Nuraini, A. (2002). Hubungan karakteristik ibu, dukungan keluarga dan pendidikan kesehatan denganperilaku pemberian ASI \& MP-ASI pada bayi usia 0-12 bulan di desa waru Jaya Kecamatan Parung Kabupaten Bogor 2002 (Tesis, tidak dipublikasikan). Fakultas Ilmu Keperawatan Universitas Indonesia, Jakarta.

Pender, N. J., Murdaugh, C. L., \& Parsons, M.A. (2002). Health promotion in nursing practice (4th Ed.). New Jersey: Practice Hall.

Perkeni. (2006). Konsensus pengelolaan diabetes mellitus di Indonesia. Jakarta: Perkeni.

Robbins, S.P. (2003). Perilaku organisasi (Jilid 1). Jakarta: PT Indeks Gramedia Group.

Setyowati, R. (2003). Beberapa faktor yang berhubungan dengan keteraturan pemeriksaan kadar gula darah pada penderita diabetes mellitus di Rumah Sakit Umum Kota Semarang (Tesis tidak dipublikasikan). FKM UNDIP, Semarang.

Siagian, S.P. (2001). Manajemen sumber daya manusia. Jakarta: Bumi Aksara.

Simon, M.G.B, Greene, W.H., \& Gottlieb, N.H. (1995). Introductionto health education and health promotion. Illionis, USA: Waveland Press Inc.

Syarif, R. (1990). Belajar mandiri dan belajar bertolak dari masalah. Bulletin Pendidikan, 1 (2), $3 b-45$.

Swanson, J.M., \& Nies, M.A. (1997). Community health nursing: Promoting the health of aggregater. Philadelphia: Saunders.

Wirakartakusumah. (2000). For elderly welfare. Jakarta: Dokumen RAN Lansia. 